\title{
Arsen i dansk drikkevand - et undervurderet sporstof
}

Af geolog Søren M. Kristiansen, Danmarks JordbrugsForskning, Forskningscenter Foulum; lektor Per Nørnberg, Geologisk Institut, Aarhus Universitet og kemiingeniør Loren Ramsay Watertech a/s, 8000 Arhus C.

Epidemiologiske undersøgelser har vist, at grundstoffet arsen selv i små mængder kan forårsage alvorlige sygdomme. Grænseværdien i drikkevand er derfor sænket til en femtedel af den tidligere værdi. Det giver en del problemer for grundvandet som drikkevandsressource.

Vores drikkevand indeholder mange forskellige grundstoffer i små koncentrationer. De fleste er sunde for os at indtage, mens nogle få kan være skadelige. Et af disse såkaldte sporstoffer er arsen. Mange naturlige forbindelser, som arsen indgår i, er yderst giftige for mennesker og dyr. Det er derfor med god grund, at der længe har været fastsat grænseværdier for arsen i bl.a. vores drikkevand.

Nyere epidemiologiske undersøgelser har imidlertid vist, at arsen i selv meget små mængder er mere sundhedsskadelig end hidtil antaget. Derfor er grænseværdien for arsen i drikkevandet fra 2004 sænket til en femtedel - fra 50 til 10 mikrogram per liter. I det vand, som vandværket sender ud, må der endda kun være $5 \mu \mathrm{g}$ arsen per liter, dvs. $5 \mathrm{~g}$ arsen opløst i 1.000.000 liter vand.

Problemet med de nye grænseværdier er, at den naturlige koncentration af arsen $\mathrm{i}$ Danmarks grundvand i gennemsnit er $3 \mu \mathrm{g}$ arsen per liter, og at indholdet i $16 \%$ af grundvandsboringerne overstiger de $5 \mu \mathrm{g}$ per liter. Arsen er således det naturligt forekommende sporstof, der oftest overskrider grænseværdierne i danske grundvandsboringer. Men heldigvis betyder denne nye grænseværdi ikke, at en stor del af vores grundvand bliver ubrugeligt som drikkevand. En del arsen fjernes nemlig allerede på vandværkerne i forbindelse med den normale vandbehandling, inden vandet sendes ud til forbrugerne. På en del vandværker, er det dog ikke nok til at komme under grænseværdien.

\section{Giftstoffet arsen}

Grundstoffet arsen tilhører gruppen metalloi-

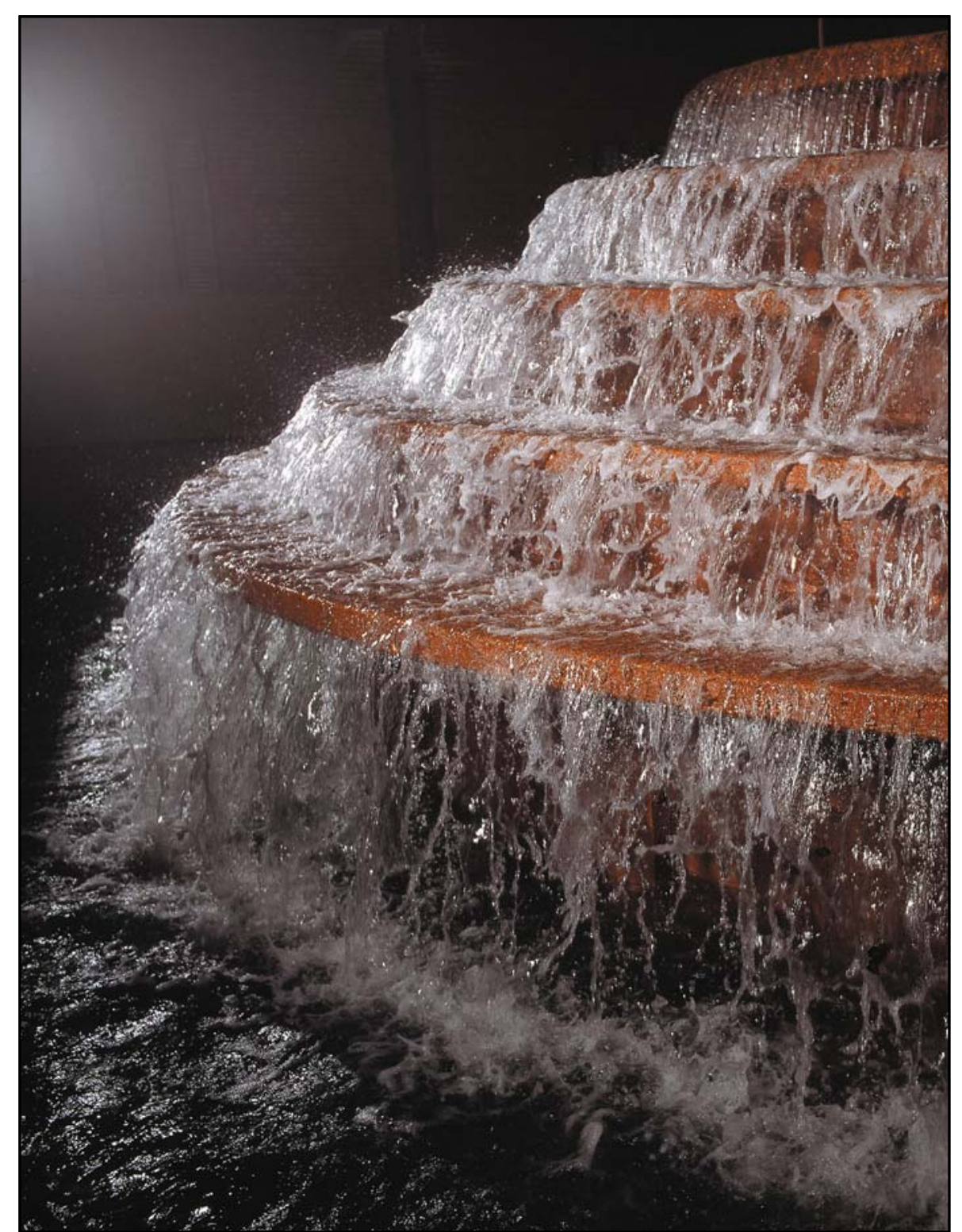

Iltningstrappe fra Søndersø vandveerk syd for Lille Varløse. (Foto: Peter Warna-Moors, GEUS)

der (halvmetaller) i det periodiske system. Kemisk ligner det således svovl og fosfor, og i naturen opfører disse grundstoffer sig ofte ens. Arsen findes naturligt overalt i jord og grundvand, men udgør mindre end $0,0001 \%$ af Jordens materialer. Der er således tale om små mængder, som dog stadigvæk kan have indflydelse på menneskers og dyrs helbred.

I naturen findes mange forbindelser, hvori arsen indgår, og disse er som nævnt alle giftige for mennesker og dyr, fordi de kan vekselvirke med proteiner og forstyre basale biokemiske processer. Dette gælder især, hvis arsen ikke allerede er bundet af organisk stof. Den bedst kendte arsenforbindelse er nok det effektive giftstof arsenik $\left(\mathrm{As}_{2} \mathrm{O}_{3}\right)$, der har været kendt i hvert fald siden middelalderen. Måske brugte romerne og grækerne det til giftmord allerede før Kristi fødsel.

Arsen var indtil ca. 1940 også en kendt medicin imod sygdomme som malaria, leukæmi, syfilis og meget andet. Men konklusionen i dag er, at brugen af arsen til disse formål dengang nok dræbte flere end det helbredte. Tidligere har arsen også været en vigtig komponent $i$ sprøjtegifte imod $\mathrm{fx}$ insekter. 
Fordeling af arsenindhold $i$ vandvarksboringer 1993-2003 vist i forhold til de geologiske aflejringer aldre end istiderne. Boringer med et indhold af arsen over gransevardien på $5 \mu \mathrm{g}$ per liter er vist med rødt. Analyse for arsen blev forst obligatorisk $i$ 2002 for vandvarkerne, hvorfor mange boringer ikke er med endnu. Fx viser nye tal at også Vest- og Sydsjcelland har mange boringer over gransevardien. GEUS er netop kommet med en ny rapport her i december. (Kilde: Grundvandsovervågning 1998-2003, GEUS 2004)

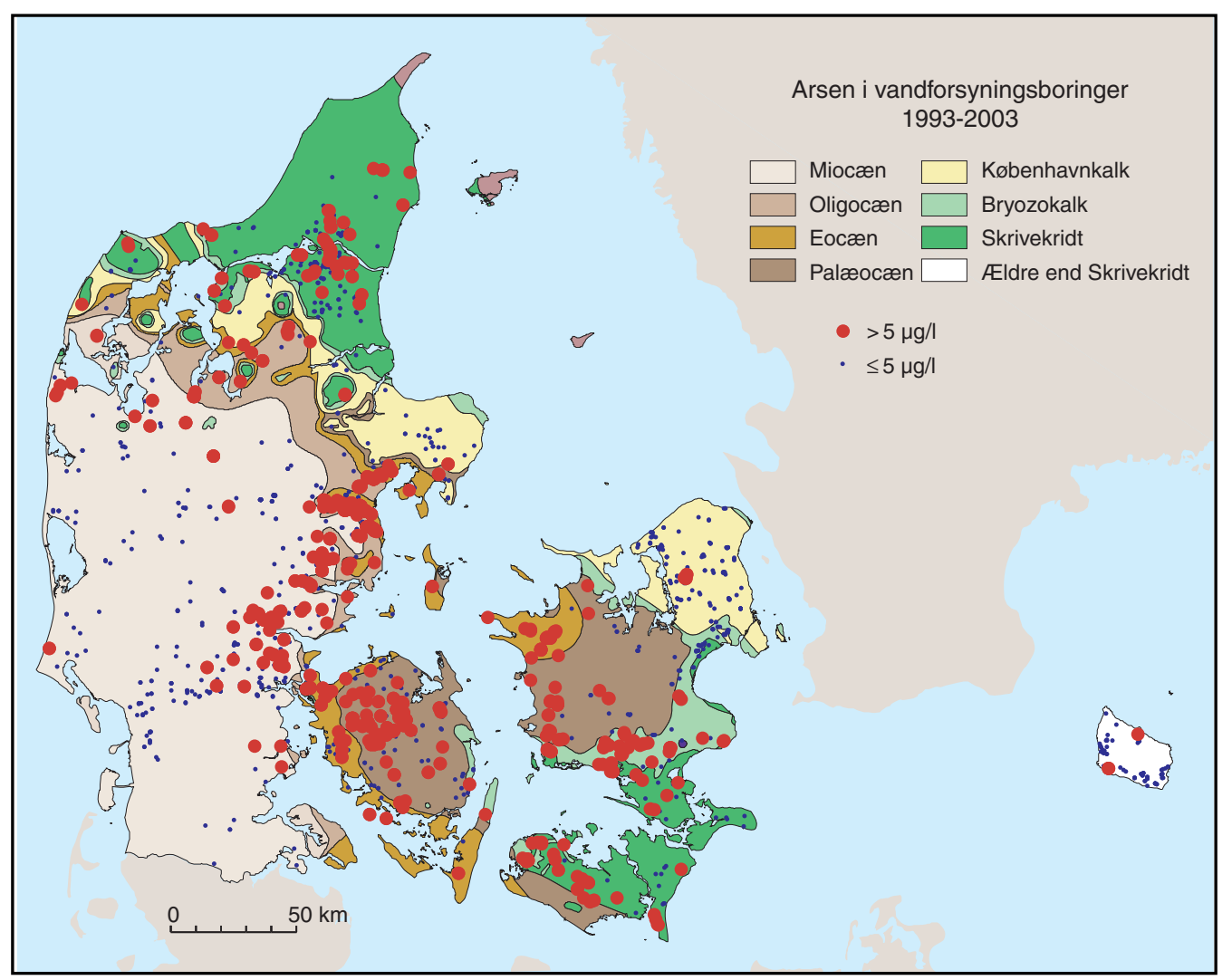

Dagligt indtager vi arsen gennem vores fødevarer og drikkevand. Den nye grænseværdi i vandet hos forbrugeren på $10 \mu \mathrm{g}$ arsen per liter vand er fastsat efter, at vi maximalt må få $20 \%$ af det daglige indtag fra drikkevandet. Hovedparten af de små mængder, vi hver dag indtager, kommer således normalt fra vores mad. Arsen i mad findes dog normalt bundet som organiske forbindelser, der er mindre giftige end de uorganiske forbindelser som dominerer i grundvandet.

\section{Vurdering af giftighed}

Når man i dag vurderer et stofs giftighed skelner man imellem giftvirkningen i naturen (en øko-toksikologisk trussel) og giftvirkningen på mennesker (en human-toksikologisk trussel). Pga. manglende undersøgelser ved man dog ikke, om naturligt forekommende arsen virker giftigt på dyr eller planter i Danmarks natur.

Giftvirkningen på mennesker deles normalt op i korttids-, dvs. akut forgiftning, og langtidseffekter, som kroniske sygdomme (bl.a. i hud, nerver, og tarm/mave) og kræft (bl.a. hud- og urinvejskræft). Akut forgiftning kræver typisk koncentrationer på $20.000 \mu \mathrm{g}$ arsen per liter, og er derfor ikke et problem i Danmark. Arsen i betydeligt lavere koncentrationer kan derimod være årsag til alvorlige sygdomme, der udvikler sig efter lang tids indtag. Dette hænger bl.a. sammen med, at arsen er vandopløselig og indtages med vand og fødevarer.

De koncentrationer på under $10 \mu \mathrm{g}$ arsen per liter, man normalt finder i Danmarks grundvand, er heldigvis væsentligt mindre end, hvad der skal til for at forårsage kroniske sygdomme ( $>100 \mu \mathrm{g}$ per liter), mens dette er set $\mathrm{i}$ andre lande $-\mathrm{fx}$ Bangladesh (se boks)

Når der alligevel er grund til at være på vagt over for arsen i Danmark, skyldes det langtidsrisikoen for at få kræft. Kræftrisikoen ved hele livet at drikke vand med de nu tilladte $10 \mu \mathrm{g}$ arsen per liter er anslået til mellem 3 per 1.000 indbyggere og 6 per 10.000 indbyggere. Den nye grænseværdi tillader dermed en sygdomsrisiko, der er op til3.000 gange højere, end den målsætning, vi typisk har for andre stoffer på eet tilfælde per million i løbet af en livstid. Den faglige baggrund bag grænseværdien er dog fortsat

\section{Arsen}

As, grundstof nummer 33, er mest kendt i form af giften arsenik $\mathrm{As}_{2} \mathrm{O}_{3}$, som bl.a. blev brugt som rottegift. Arsenforbindelser blev desuden i mange år brugt til at trykimprægnere træ, men det er strengt forbudt nu. Det er ikke alle arsenforbindelser, der er lige giftige. Skaldyr og fisk indeholder fx mindre giftige organiske arsenforbindelser.

I grundvandet er arsen dog normalt bundet i uorganiske forbindelser. I iltholdige miljøer findes arsen primært bundet som arsenat $\left(\mathrm{H}_{3} \mathrm{AsO}_{4}^{-}\right)$, mens arsenit $\left(\mathrm{H}_{2} \mathrm{AsO}_{3}{ }^{0}\right)$ dominerer i iltfrie miljøer. Som det også fremgår af kortet, mener man, at arsen $i$ grundvandet ofte stammer fra mineraler i lerede, marine sedimenter, der er mange millioner år gamle - mere specifikt fra tidsperioderne Paleocæn, Eocæn og Oligocæn.

En stor del af jordens arsen er bundet til overfladerne på jordens mineraler. Især bindes arsen hårdt af visse jernholdige hydroxider som ferrihydrit $\left(\mathrm{Fe}_{2} \mathrm{O}_{3} \cdot 2 \mathrm{H}_{2} \mathrm{O}\right)$ og sulfider som pyrit $\left(\mathrm{FeS}_{2}\right)$. Men når ferrihydrit kommer fra et iltrigt til et iltfattigt miljø, vil mineralet kunne opløses og arsen dermed blive frigivet til grundvandet som opløst stof. I Danmark er ferrihydrit meget almindeligt, og opløsning af mineralet mistænkes derfor for at være en vigtig kilde til arsen i drikkevandet.

Selvom arsen findes i små mængder kan man i laboratoriet let måle det totale indhold. Det er straks mere vanskeligt, hvis man ønsker at måle mængden af de forskellige organiske og uorganiske forbindelser. Her skal man nemlig være uhyre forsigtig for ikke at påvirke kemien og dermed ligevægten imellem dem, når prøven flyttes fra naturen til laboratoriet.

I laboratoriet forsøger man at forstå arsens geokemiske opførsel i naturen vha. metoder, der efterligner forskellige kemiske og fysiske miljøer. Her kan man fx bestemme mængden af arsen, der frigives fra hydroxider i et iltfrit miljø eller mængden, der let frigives fra sulfider og organisk stofi et iltrigt miljø. 
til diskussion. Dette skyldes især, at det er svært at fastslå den reelle sundhedsrisiko, man udsættes for ved små koncentrationer af et stof.

\section{En ny begrænsning}

De relativt høje koncentrationer af arsen i vore grundvandsboringer skyldes primært naturlige kilder, og er sjældent menneskeskabte. Arsen findes dog som menneskeskabt forurening nogle steder, bl.a. fordi arsenforbindelser tidligere blev brugt til imprægnering af træ. Dette er dog et mindre problem for drikkevandet, da vi ved, hvor de forurenede grunde findes og dermed kan tage vores forholdsregler.

Vores viden om naturligt forekommende arsen er derimod begrænset. Vi ved dog, at det findes i højere koncentrationer i iltfrit end i iltholdigt grundvand. Høje koncentrationer findes også i visse områder, hvor man indvinder vandet fra bestemte geologiske lag. Tilsammen tyder det på, at arsen i grundvandet ofte stammer fra mineraler $i$ lerede, marine sedimenter, der er mange millioner år gamle - mere specifikt fra tidsperioderne Paleocæn, Eocæn og Oligocæn (se boks). Desværre findes disse lag ofte i, eller lige under, de vandførende lag, hvorfra vi gerne vil hente grundvand.

Problemet med den nye lavere grænseværdi for arsen forstærkes således af, at geologien og geokemien kan sætte en ny nedre grænse for, hvor vi kan indvinde grundvand til drikkevand. Populært sagt er drikkevandsressourcen i dag begrænset af, at ungt, overfladenært grundvand ofte inde-

\section{Arsen $i$ Bangladesh}

Da Bangladesh opnåede uafhængighed i 1971, var det et fattigt land med meget høj børnedødelighed som følge af bl.a. underernæring og sygdomme forårsaget af dårlige sanitære forhold - herunder forurenet drikkevand. Derfor iværksatte vestlige hjælpeorganisationer fra bl.a. Danmark et storstilet program med udførelse af grundvandsboringer for at undgå brug af forurenet overfladevand, samt opførelse af latriner til at forbedre de sanitære forhold. Men først i 1993 opdagede man, at der var arsen i grundvandet og ofte i størrelsesorden flere hundrede $\mu \mathrm{g}$ per liter. Arsen fra boringerne har medført mange tilfælde af kroniske sygdomme og mere end 25 millioner indbyggere er i dag udsat for forhøjede koncentrationer. Dette har resulteret i, at mange drikkevandsboringer er opgivet til fordel for overfladevand. I dag er børnedødeligheden i Bangladesh stadigvæk meget høj.

Geokemien kan forklare, hvordan arsen kan ende $i$ drikkevan det, når man pumper grundvand op fra dybe jordlag med iltfrie (reducerende) forhold. (Grafik: Forfatterne)

holder for meget nitrat eller for mange pesticider, mens det dybe grundvand visse steder nu indeholder for meget arsen.

\section{Hvad kan vi gøre?}

Heldigvis har det vist sig, at den allerede eksisterende rensning for opløst jern på vandværkerne også fjerner en del arsen. Hvor meget arsen, der fjernes, inden det sendes ud til forbrugerne, varierer dog kraftig fra grundvandstype til grundvandstype og fra vandværk til vandværk.

Øget viden om arsen kan i fremtiden måske bidrage til, at man allerede ved valg af borelokalitet og ved filtersætningen i boringen kan undgå sedimenter og/eller geokemiske forhold, hvor der potentielt er for høje koncentrationer af arsen. Nye metoder til at fjerne arsen på vandværkerne, kan også bidrage til løsning af det human-toksikologiske problem.

Selvom den nye viden om arsen i drikke- vand kan lyde som en trussel mod folkesundheden, så er der grund til optimisme. Koncentrationen i Danmark er meget lavere end i de lande, hvor sygdomstilfælde er set. Og fremover kan vi sandsynligvis mindske arsen-indholdet $i$ vandet på vandværkerne. Alene ud fra et forsigtighedsprincip, bør vi begrænse indholdet af arsen i vores drikkevand mest muligt.

\section{Yderligere laesning}

Larsen, C.L., F. Larsen: Arsen i danske sedimenter og grundvand, 2003, Vand \& Jord, vol. 11, 4: 147-151.

Nordstrom, D.K.: Worldwide occurrences of arsenic in groundwater, 2002,

Science, vol. 296: 2143-2145.

Rapporten Grundvandsovervågning 2004, Danmarks og Grønlands Geologiske Undersøgelse, GEUS. 